\title{
LOS EMBATES DE LA GLOBALIZACIÓN A LA DEMOCRACIA ${ }^{1}$ \\ Globalization's onslaught on democracy
}

\author{
JOSÉ LUIS GARCÍA GUERRERO \\ Universidad de Castilla-La Mancha \\ joseluis.gguerrero@uclm.es
}

Cómo citar/Citation

García Guerrero, J. L. (2017).

Los embates de la globalización a la democracia.

Revista de Estudios Políticos, 176, $113-146$

doi: https://doi.org/10.18042/cepc/rep.176.04

\section{Resumen}

El último embate empírico a la democracia viene dado por la globalización. Bajo el término democracia se engloba la afección que se origina a la distinción entre poder constituyente y constituido, a la soberanía popular, al valor del pluralismo político y al carácter abierto de las normas constitucionales, al principio democrático, a la regla de la mayoría y la minoría y, en consecuencia, al derecho fundamental a la participación política.

Este trabajo intenta determinar la intensidad de la afección a las diferentes figuras que se engloban bajo la rúbrica democracia en las cinco fases de la primera etapa de la globalización y en la segunda etapa de la misma, al tiempo que se buscarían soluciones que contribuyan a superar y, en su caso, disminuir el ataque a la democracia.

\section{Palabras clave}

Globalización; integración económica supranacional; embate a la democracia.

1 Este artículo se enmarca en el proyecto de investigación «Constitución y mercado en la crisis de la integración europea», DER2013-48327-C3-1-R (MINECO 2014-2016). Una síntesis de este proyecto en García Guerrero y Martínez Alarcón (2016: 15-21). El artículo fue defendido en inglés como ponencia invitada en The 3rd Meeting of the Network on Transnational Legal and Political, en Cartagena de Indias el 27 de agosto de 2016 y, en español, el día 24 del mismo mes en el Congreso sobre Globalización. 


\section{Abstract}

The lastest empirical onslaught on democracy comes from globalization. Democracy encompasses Constitutional power, popular sovereignty, the values of political pluralism, the openness and transparency of the constitutional norms, and the democratic principle of the fundamental right to political participation. The paper seeks to explain the intensity of the damage done to democracy term the five different phases of the first stage of globalization and in its second stage. At the same time, the paper looks for solutions in order to overcome the problem to try to diminish the attack on democracy.

\section{Keywords}

Globalization; supranational economic integration; onslaughts against democracy. 


\section{SUMARIO}

I. INTRODUCCIÓN. II. LA GLOBALIZACIÓN. 1. La primera etapa de la globalización: los diferentes tipos de integraciones supraestatales. 2. La segunda etapa de la globalización: los acuerdos entre bloques económicos. III. EL PROGRESIVO EMBATE A LA DEMOCRACIA SEGÚN LA INTENSIDAD DE LA GLOBALIZACIÓN. 1. Algunas precisiones previas. 2. Poca afección en el acuerdo de libre comercio. 3. En la unión aduanera y en el camino al mercado común. 4. En la unidad económica y/o monetaria supraestatal. 5. En la segunda etapa de la globalización, en los acuerdos entre bloques económicos. 6. El ataque a la democracia no afecta por igual a todos los estados. 7. Algunas reglas o conclusiones sobre cómo la globalización afecta a la democracia. IV. ¿̇PUEDE OFRECER EL DERECHO CONSTITUCIONAL ALGUNA RESPUESTA AL EMBATE A LA DEMOCRACIA? BREVE REFLEXIÓN. BIBLIOGRAFIA.

\section{INTRODUCCIÓN}

La democracia ha sufrido numerosos ataques teóricos y empíricos que, con mayor o menor dificultad, ha logrado superar. El último embate empírico viene dado por la globalización.

Cuando desde una perspectiva constitucional se profundiza en la globalización se puede apreciar que, en realidad, este fenómeno no solo ataca la democracia sino, más ampliamente, al propio concepto racional normativo de constitución. A medida que se intensifica la globalización resultan afectados, en mayor o menor medida, los valores y los derechos fundamentales, los derechos constitucionales y, entre ellos muy especialmente, los de los trabajadores, la constitución económica, así como el propio Estado social e, incluso, algunos mandatos constitucionales como la protección del medio ambiente.

Este amplio objeto de afección por la globalización, cuya mención no ha pretendido ser exhaustiva, no puede afrontarse en un artículo, por lo que el mismo quedaría acotado al embate que la globalización origina a la democracia. Bajo este término se engloba la afección que se origina a la distinción entre poder constituyente y constituido, a la soberanía popular, al valor del pluralismo político y al carácter abierto de las normas constitucionales, al principio democrático, a la regla de la mayoría y la minoría y al derecho fundamental a la participación política.

No obstante, el ataque presenta diferente intensidad en las distintas figuras que se han englobado bajo la rúbrica de democracia. Además, se estima 
que en la globalización son discernibles dos etapas: una primera en que cabe distinguir, acuerdo de libre comercio, unión aduanera, mercado común, unidad económica supraestatal y, probablemente, unidad económica y monetaria supraestatal; la segunda etapa de la globalización se diferencia por los actores (integraciones económicas, potencias, expotencias, emergentes), por la existencia de órganos de gobierno, por la intensa implementación legislativa que conlleva y por la creación de órganos jurisdiccionales o arbitrales para dirimir las controversias del acuerdo de libre comercio e inversiones.

En consecuencia, este trabajo trataría de determinar la intensidad de la afección a las diferentes figuras que se engloban bajo la rúbrica democracia en las cinco fases de la primera etapa de la globalización y en la segunda etapa de la misma, al tiempo que se buscarían soluciones que contribuyan a superar $y$, en su caso, disminuir el ataque a la democracia.

\section{LA GLOBALIZACIÓN}

El Diccionario de la Real Academia de la Lengua Española define globalización como: «Tendencia de los mercados y las empresas a extenderse alcanzando una dimensión mundial que sobrepasa las fronteras nacionales». Aunque hay claros antecedentes de la globalización desde los inicios del capitalismo, éstos no contaban con las garantías y con el marco jurídico de seguridad que aporta la constitución racional normativa. Por esta razón puede señalarse que la globalización ${ }^{2}$ se inicia inmediatamente a continuación de la caída del Muro de Berlín, concretamente en los primeros años noventa del siglo pasado. Las empresas empiezan a sentirse incómodas en el marco de la unidad económica nacional $^{3}$ y más específicamente en su correlato, la unidad de mercado; que implica, de una parte, la libertad de circulación de mercancías, capitales, servicios y mano

2 Véanse las aproximaciones constitucionales de García Guerrero (2005: 135-155, 2014a: 544-591), Viciano Pastor (2009) y Brewer-Carias (1998 y 1999).

3 La STC 1/1982, FJ 1, afirma a propósito de la unidad económica nacional: el marco que impone la constitución económica «implica la existencia de unos principios básicos del orden económico que han de aplicarse con carácter unitario, unicidad que está reiteradamente exigida por la Constitución [...] Esta exigencia de que el orden económico nacional sea uno en todo el ámbito del Estado es más imperiosa en aquellos, como el nuestro, que tienen estructura interna no uniforme, sino plural o compuesta desde el punto de vista de su organización territorial (Tít. VIII de la CE). La unicidad del orden económico nacional es un presupuesto necesario para que el reparto de competencias entre el Estado y las distintas Comunidades Autónomas no conduzca a resultados disfuncionales o desintegradores». 
de obra, y, de otra parte, la igualdad en las condiciones básicas de ejercicio de la actividad económica ${ }^{4}$.

La Organización Mundial del Comercio (OMC), para satisfacer a estas empresas, persiguió la liberación multilateral del comercio, con el GATT de 1994 y con el Acuerdo general sobre el comercio de servicios, pero tras el fracaso de esta iniciativa promovió decididamente las integraciones económicas supraestatales (supranacionales) ${ }^{5}$ que consiguen, en una primera fase, en un ámbito territorial más reducido el mismo objetivo. El deseo de globalización se acentuaba en una primera fase por la apertura de inmensos mercados en Europa y Asia, tras la caída del Muro de Berlín, que se vieron incrementados en una segunda tras adoptar China, Vietnam y, más incipientemente en la actualidad, Cuba, el lema de «un Estado, dos constituciones económicas»: la liberal y la marxista.

\section{LA PRIMERA ETAPA DE LA GLOBALIZACIÓN: LOS DIFERENTES TIPOS DE INTEGRACIONES SUPRAESTATALES}

Ahora bien, es conveniente precisar que no todas las integraciones económicas supraestatales son iguales ${ }^{6}$, al diferenciarse claramente por su intensidad. Según la opinión más extendida hay cuatro, aunque tras las últimas investigaciones ${ }^{7}$ se mantiene una duda razonable sobre la conveniencia de diferenciar dentro del cuarto tipo un quinto.

El primer tipo son los acuerdos de libre comercio, que encuentran un contexto favorable en el fin de la Guerra Fría y en el fracaso de la liberalización multilateral, que encontró una favorable alternativa en los acuerdos de integración regional. Su triunfo viene marcado por el reconocimiento de que los modelos de sustitución de importaciones, que implicaban el cierre de fronteras, no estaban generando las altas tasas de crecimiento económico de las últimas décadas; y por las grandes ventajas que se obtienen de la especialización en ciertas industrias y bienes e, incluso, en sectores de dichas industrias, lo que incrementa las economías de escala con la posibilidad de empleos mejor remunerados, al aumentar el volumen de producción y reducirse el precio de los productos.

\footnotetext{
$4 \quad$ STC 88/1986, FJ 6.

5 La doctrina utiliza la expresión integración supranacional; sin embargo, este autor defiende como más correcto el término supraestatal, porque hay numerosos Estados plurinacionales.

6 Lawrence (1996).

7 García Guerrero (2017a).
} 
Los acuerdos de este tipo se caracterizan por la reducción, cuando no eliminación, de las barreras arancelarias a los productos comerciales. Se persigue la libre circulación de mercancías y, en la medida de lo posible, de servicios.

En este primer tipo de integración resultan afectadas ciertas potestades de los Ejecutivos y, en menor medida, legislativas y judiciales. La unidad de mercado abandona su marco estatal en el ámbito de las mercancías y de los servicios afectados y pasa a corresponderse con el ámbito territorial de la integración. Empiezan a surgir los primeros problemas para que el Parlamento pueda controlar al Ejecutivo en estos ámbitos materiales.

El tipo siguiente son las conocidas uniones aduaneras, que se caracterizan por una mayor profundización de la integración, por reducirse o, más bien, eliminarse los aranceles entre los Estados contratantes y por fijar unos comunes frente al exterior; se busca una política comercial común, que al final queda en manos de las autoridades surgidas de los acuerdos supraestatales.

En la unión aduanera las consecuencias constitucionales anteriores se intensifican; la política comercial queda en manos de los acuerdos supraestatales, sustrayéndose este ámbito del campo de juego político, con la consecuente reducción del pluralismo político. Cuando se decide dirigir la unión aduanera hacia un mercado común, que es lo más usual, el acuerdo de integración económica supraestatal se convierte en derecho primario, del que surgirá un derecho derivado. Se ceden competencias soberanas de naturaleza legislativa, ejecutiva y judicial a órganos supraestatales creados por el acuerdo internacional. Aparecen poderes ejecutivos, legislativos y judiciales propios de la organización supraestatal; la diferenciación entre poder constituyente y constituido, la soberanía popular, el pluralismo político, el principio democrático y el derecho fundamental a la participación política comienzan a resultar afectados, con mayor intensidad a medida que la integración se aproxima a la fase de mercado común.

El tercer tipo es el mercado común, que implica una política comercial común y una completa liberalización de los factores de producción, es decir, la libre circulación de mercancías, servicios, capitales y mano de obra; se requiere, además, libre competencia e igualdad en las condiciones básicas de ejercicio de la actividad económica. También es necesario crear una cierta infraestructura monetaria, para evitar devaluaciones competitivas no deseadas por el resto de los socios de la integración. Se crea un nuevo ordenamiento supraestatal que debería relacionarse con los ordenamientos de los Estados miembros principalmente a través del principio de competencia ${ }^{8}$. El mercado común tiene órganos ejecutivos, legislativos y judiciales propios.

8 La relación entre el ordenamiento supraestatal y los ordenamientos de los Estados de la integración es una cuestión polémica y plagada de estudios doctrinales por 
Las consecuencias constitucionales de la fase de mercado común son las mismas que cuando la unión aduanera se dirige a constituirse en un mercado común, aunque en su máxima intensidad. Por último, aunque no por ello menos importante, se reduce sustancialmente el régimen de discrecionalidad estatal en las políticas monetarias.

El cuarto tipo de integración, que cabría denominar como unidad económica supraestatal, conlleva las mismas exigencias que el mercado común, pero este se transforma en mercado único, esto es, el principio de unidad económica nacional y su correlato, la unidad de mercado, ven ampliado su ámbito territorial, que pasa del estatal al que se corresponde con el ámbito territorial de la unidad económica supraestatal. Se profundiza en la infraestructura monetaria y se exige una armonización de las políticas macroeconómicas y fiscales, al tiempo que se requieren determinadas políticas regulatorias. Las afecciones a la democracia son difícilmente sostenibles. Esta fase de la integración solo se ha alcanzado en la Unión Europea.

No obstante, la Unión Europea había decidido profundizar en el mercado único, sustituyendo la infraestructura monetaria creada por sus propias divisas por una moneda propia y un Banco Central. Una parte de los países de la Unión, con Gran Bretaña al frente, renunció a esta fase (lo que obliga a tener presente el derecho de la Unión y los acuerdos intergubernamentales de los Estados de la eurozona), en parte por las consecuencias constitucionales referidas. El paso supone transferir desde los Estados a los órganos de la integración la práctica totalidad de sus competencias en política monetaria, y eliminar el pluralismo político y la discrecionalidad en las políticas macroeconómicas y fiscales estatales, que vienen determinadas por los

diversas disciplinas jurídicas. El Tribunal de Justicia de la Unión Europea en su Sentencia de 15.07.1964, asunto 6/64, Costa Enel (única integración que ha perfeccionado la fase de Mercado Común), sostiene que hay primacía del ordenamiento de la Unión; en el mismo sentido, recientemente, la Sentencia de 15.01.2013, asunto C-416/10 Krizan e.a. versus Slovenska, apartado 70. El Tratado de la Unión Europea (TUE, artículo 5) no se atrevió a llegar tan lejos y consagró el principio de atribución. Para evitar un ataque al principio democrático, el autor de estas líneas sostiene que se debe aplicar el principio de competencia. En esta materia es clave la Decisión del Tribunal Constitucional 1/2004 y el trabajo de López Castillo et al. (2005), que, al hilo del profundo análisis de la Declaración, permite comprender las razones que llevan a estos autores a no integrar el ordenamiento de la Unión y el de los Estados miembros bajo el principio de competencia en sentido estricto. En cambio, el autor de estas líneas sostiene que se debe aplicar el principio de competencia. A propósito de estas tres posiciones, véanse sus trabajos (2014b: 454-480, más recientemente, 2014c: 150-152). 
órganos de gobierno de la integración' 9 . El incumplimiento por cualquier Estado de estas políticas macroeconómicas y fiscales origina que estas pasen a ser codecididas entre los órganos de la integración y las autoridades estatales, teniendo, en caso de discrepancia, la última palabra los primeros que dictarían las pertinentes políticas regulatorias ${ }^{10}$. La trascendencia de estas transformaciones constitucionales es lo que parece aconsejar la creación de un quinto tipo de integración, que podría denominarse unidad económica y monetaria supraestatal. Las dudas para consolidar este tipo surgen porque solo se ha alcanzado esta fase, al igual que en la anterior, en la integración europea y, en consecuencia, la teoría resulta excesivamente dependiente del método fenomenológico.

\section{LA SEGUNDA ETAPA DE LA GLOBALIZACIÓN: LOS ACUERDOS ENTRE BLOQUES ECONÓMICOS}

En la primera aproximación a esta materia en $2005^{11}$ se pensaba que hasta aquí llegaba la globalización, es decir, que la tendencia de las empresas y los mercados en superar el marco estatal iba a quedar satisfecha con integraciones económicas supraestatales cada vez más intensas. No obstante, en $2013^{12}$ ya se pudo afirmar que esta era la primera etapa de la globalización; se encuentra en plena evolución y encuentra un fuerte aliento en los nuevos e inmensos mercados que se abren especialmente en China y en menor medida en Vietnam y, de forma incipiente, en Cuba (han adoptado junto a la constitución económica marxista, la liberal). La globalización presenta una segunda etapa que se caracteriza principalmente por el cambio de sus actores, los Estados, como regla general, ya no son protagonistas, con las relevantes excepciones de Estados Unidos y dos emergentes: Rusia y China,

9 Menéndez Menéndez considera, con acierto, que una moneda única implica una específica configuración de la política económica en general y que esta infraestructura monetaria reclamaría: «(1) Una única y supranacional política monetaria para toda la Eurozona; (2) La disciplina supranacional de las políticas fiscal y macroeconómica de todos los estados» y mucho más intensa para los de la eurozona. «(3). La supervisión macroprudencial del sistema financiero europeo y la supervisión microprudencial de las instituciones financieras de la Eurozona [...] (4) los mecanismos, estructuras y recursos mediante los que los Estados de la Unión Europea, y muy especialmente los de la Eurozona, se prestan asistencia financiera en determinadas circunstancias y sujetas a condiciones estrictas» (2015: 139).

10 Menéndez Menéndez (2015: 155-160).

11 García Guerrero (2005: 135-155).

12 García Guerrero (2014a: 544-591). 
el resto de actores, al menos en una de las partes, son los ejecutivos de las integraciones económicas supraestatales.

La segunda etapa de la globalización se singulariza por la firma de acuerdos, tratados y convenios internacionales económicos entre estos actores. Hasta ahora, estos se han limitado a acuerdos de libre comercio, esto es, a la primera fase de la integración. No obstante, habrá que estudiar con detenimiento estos nuevos acuerdos de libre comercio, pues hay elementos que hacen sospechar que son diferentes a los de la primera etapa de la globalización. En general, parece que la integración es bastante más profunda, así parece manifestarse en la creación de un órgano más o menos ejecutivo, en la intensa implementación legislativa que exigen y en la creación de órganos arbitrales o judiciales. Cuestión esta última que se está dirimiendo en la actual fase de negociación del Acuerdo Transatlántico de comercio e inversiones entre la Unión Europea y Estados Unidos (TTIP) ${ }^{13}$.

Es razonable pensar que estas integraciones de la segunda etapa de la globalización se intensifiquen en el futuro y pasen a las siguientes fases: unión aduanera, mercado común, unidad económica supraestatal y unidad económica y monetaria supraestatal. El límite que pueda alcanzar la globalización y sus acuerdos de integración no puede vislumbrarse hoy con seguridad, pero no cabe descartar que, en el largo plazo, se pretenda alcanzar la unidad económica mundial. Ahora bien, debe advertirse que pasar de unión aduanera a Mercado Común no es tarea fácil, ni siquiera en la primera etapa de la globalización, fundamentalmente porque exige una cierta infraestructura monetaria, lo que explica que este objetivo solo se haya alcanzado en Europa, fracasara en su día en el Pacto Andino y no se haya conseguido todavía en Mercosur.

\section{EL PROGRESIVO EMBATE A LA DEMOCRACIA SEGÚN LA INTENSIDAD DE LA GLOBALIZACIÓN}

\section{ALGUNAS PRECISIONES PREVIAS}

Las dos etapas de la globalización suponen el último embate al concepto racional normativo de Constitución. No es aquí el lugar de afrontar esta cuestión, por lo que se dejan fuera importantes cuestiones como la desconstitucionalización de las Constituciones económicas ${ }^{14}$, el ataque al Estado social ${ }^{15}$, a los derechos constitucionales de prestación o a los

\footnotetext{
13 Taibo (2016).

14 García Guerrero (2017a).

15 De Cabo (2009) y Tajadura Tejada (2006).
} 
derechos sociales de los trabajadores ${ }^{16}$, entre otras. Este trabajo se circunscribe, predominantemente, a las consecuencias que las dos etapas de la globalización tienen sobre la democracia, especialmente en gobiernos parlamentarios. Al analizar la primera etapa y al hilo de las diferentes fases de integración se ha dicho algo ya; es ahora el momento de recapitular y precisar estas consecuencias. Ahora bien, para poder realizar esta tarea se deben recordar previamente dos extremos.

En primer lugar, que el Pacto Andino ${ }^{17}$, en su momento, y actualmente Mercosur se han aproximado a la fase de Mercado Común lo suficiente, sin alcanzarla, para permitir sintetizar una teoría de las tres primeras fases de integración, pero la cuarta y la quinta solo se han conseguido en la Unión Europea, por lo que esta debe tomarse como referencia.

En segundo lugar, se debe recordar que hay diversas formas de democracia, por lo que es necesario precisar de qué presupuestos se parte en este trabajo y qué postulados defiende su autor.

El concepto racional normativo de Constitución ${ }^{18}$ pronto descartó que el principio democrático se pudiera realizar a través de la democracia directa. No solo por la imposibilidad de reunir a millones de personas, que deliberen y voten, sino, fundamentalmente, porque este tipo de Norma Fundamental reconoce el conflicto $^{19}$ y es una Constitución de integración ${ }^{20}$ y esta no es posible con la democracia directa. Por esta razón, desde sus inicios se adoptó la democracia representativa ${ }^{21}$, que conoce de

16 Menéndez Menéndez relata cómo en lo que a la Unión Europea se refiere: «La política social orientada a la protección de la parte más débil en las relaciones económicas fue progresivamente reemplazada por una política social orientada a fomentar la productividad y la competitividad exterior, como quedó ya reflejado en la llamada Estrategia de Lisboa de 2000» (2015: 173).

17 Contipelli (2016: 261-280).

18 García Pelayo (1984: 34 y ss.).

19 La Norma Fundamental reconoce el conflicto y fija las reglas de juego y el campo en que la confrontación de intereses se debe realizar, como han recordado Hesse y Dahrendorf (Hesse, 1983: 9).

20 Sobre el papel de integración de la Constitución y de la democracia representativa ante el conflicto por los diversos intereses sociales que se confrontan, véase Smend (1985), especialmente en lo relativo a la Constitución como norma de integración. Sobre la insuficiencia de la democracia directa en la integración, véanse Aragón Reyes (1989: 105 y ss.), Kriele (1980: 320 y ss.) y Böckenförde (1985). Este último trabajo se puede consultar en lengua italiana (1985: 227-263).

21 Así lo ha reconocido, entre otros muchos sistemas, la Unión Europea, que lo establece en el Tratado de la Unión Europea (TUE), concretamente en su artículo 10.1, «El 
dos formas: la democracia representativa liberal y la de partidos. En la primera el principio democrático se realiza políticamente y en la segunda jurídicamente ${ }^{22}$.

Algunas constituciones iberoamericanas han querido introducir una tercera, la democracia participativa, que en el mejor de los casos es una desafortunada reelaboración de la democracia representativa de partidos; $y$ en el peor de los casos supone una deriva a posiciones autoritarias, poco conciliables con el valor libertad, enmascaradas en el principio asambleario y la revocatoria; y a veces, incluso, negando a los propios partidos políticos como instrumento imprescindible de la democracia.

Todas las constituciones occidentales reconocen una de las dos formas de democracia representativa posibles y adoptan, expresa o implícitamente (especialmente las liberales), el derecho fundamental a la participación política que incluye entre su contenido el derecho al sufragio activo y pasivo. Además, estas constituciones, ante la imposibilidad de realizar la democracia directa, contienen diferentes institutos de democracia directa (iniciativa legislativa popular y diferentes tipos de referéndum).

La democracia representativa, cuando adopta la forma de gobierno parlamentario, exige que los Parlamentos ostenten la función legislativa, entendida en sentido amplio, y el control del Ejecutivo.

También es necesario recordar que la soberanía ${ }^{23}$ se ejerce en un marco estatal, ya sea este unitario, regional, autonómico o federal, y que desde una concepción dogmáticamente rigurosa la soberanía no es divisible y resulta difícil admitir categorías como la soberanía compartida ${ }^{24}$.

La naturaleza jurídica del tipo de norma empleado para la integración, tratado internacional, impide mantener la distinción entre poder constituyente y constituido. Esta naturaleza lleva a normas cerradas que buscan la seguridad jurídica, frente a las normas constitucionales que son abiertas y permiten así mantener un margen de pluralismo político, otorgando la suficiente discrecionalidad al legislador para que pueda actuar el principio democrático

funcionamiento de la Unión se basa en la democracia representativa».

22 García Guerrero (2000: 575 y 2017b: 491). Del mismo autor, pero con mayor profundidad doctrinal, (1996: 119-152).

23 Heller (1965) y Wyduckel (1998). Un análisis de la soberanía en el contexto de la globalización en Krasner (2001) y Sassen (2001).

24 El término «soberanía compartida» ha disfrutado de gran predicamento en la Unión Europea para explicar su déficit democrático. Ha sido utilizado también reiteradamente en España como forma de superar el contencioso con el Reino Unido, a propósito de Gibraltar. 
a través de la regla de la mayoría y la minoría ${ }^{25}$, haciendo efectivo el derecho fundamental a la participación política.

Si se parte de la Constitución española, a modo de ejemplo, puede concluirse que el legislador optó, dentro de la discrecionalidad que le confirió el constituyente, por la democracia representativa de partidos ${ }^{26}$. En esta forma el principio democrático se realiza dominantemente a través de estas organizaciones políticas que tienen como función principal sintetizar en el plano estatal las múltiples voluntades populares (pluralismo político) en una sola (la voluntad estatal). Esta Norma de normas constitucionalizó el pluralismo político, el principio democrático y el derecho fundamental a la participación política. Este derecho puede ejercitarse directa o indirectamente. La democracia indirecta engloba el derecho al sufragio activo y pasivo, esto es, a través de representantes. La democracia directa incluye la iniciativa legislativa popular y diferentes tipos de referéndum que se basan en el sufragio activo, a decir de la mayor parte de la doctrina.

No obstante, en anteriores publicaciones ${ }^{27}$ se estima haber demostrado que en una democracia representativa de partidos, como la española, la democracia directa no se agota en sus principales institutos, sino que debido a la conexión sistemática entre los artículos 6 («Los partidos políticos [...] son instrumento fundamental para la participación política...») y 23 («Los ciudadanos tienen el derecho a participar en los asuntos públicos, directamente o por medio de representantes libremente elegidos en elecciones periódicas...»), la representación directa se extiende a toda la actividad que un militante puede desarrollar en el interior del partido ${ }^{28}$, buena parte de ella configurada legislativamente como contenido del artículo 23 (se trata de un derecho fundamental de configuración legal ${ }^{29}$ ), y entre la que destaca la relativa a su participación directa en la elaboración del programa y en la elección de los candidatos que el partido presentará en las elecciones.

25 Kelsen (2002: 61-81, más específicamente en la p. 66, aunque lo denomina principio, en lugar de regla).

26 García Guerrero (1996: 143-149, más sintéticamente p. 171).

27 García Guerrero (1990: 153-154).

28 El Tribunal Constitucional no ha llegado a afrontar la cuestión directamente, aunque en la STC 63/1987, FJ 5, no incluye entre la participación directa la que el militante realiza en el interior del partido. Torres del Moral se muestra contrario a la tesis aquí defendida (1988). En cambio, la STC 30/1983, entre otras muchas, ampara en virtud del artículo 23 la inconstitucionalidad de la pérdida del acta de concejal a consecuencia de la expulsión de su partido, el PNV. 
En definitiva, el derecho fundamental a la participación política en España englobaría el sufragio activo y pasivo en las elecciones municipales, autonómicas, nacionales y europeas, así como el activo en los distintos tipos de referéndum que puedan convocarse. Finalmente, este derecho abarcaría la iniciativa legislativa popular y la importantísima participación que puede desarrollarse en el interior del partido político, utilizado instrumentalmente por aquellos individuos que tienen una mayor propensión a participar en los asuntos públicos ${ }^{30}$.

\section{POCA AFECCIÓN EN EL ACUERDO DE LIBRE COMERCIO}

Cuando se firma un acuerdo de libre comercio de la primera etapa de la globalización, en las formas de gobierno parlamentario, el poder legislativo es sustituido por el ejecutivo en la regulación relativa a las mercancías y a los servicios afectados que se contienen en un tipo de norma: el tratado internacional. El Parlamento no legisla sobre estas materias, lo hace el Ejecutivo; el legislador, al igual que en un decreto $l e y^{31}$, se ve obligado a aceptar o rechazar el todo. Además, el legislativo pierde estas competencias pro futuro, al menos, hasta la denuncia del tratado. Por su parte, el Ejecutivo no es soberano en la regulación, sino que esta depende del acuerdo entre los gobiernos de diferentes Estados. El Ejecutivo en el futuro estará limitado en su potestad reglamentaria por el tratado mientras este no sea denunciado. Estas limitaciones al Gobierno restringen la capacidad que tiene el Parlamento para controlarlo. El resultado es que sobre este ámbito material los ciudadanos del Estado pasan a compartir su soberanía con los demás países de la integración, lo que es difícilmente conciliable con la dogmática de la soberanía; la naturaleza jurídica de las normas sobre tratados internacionales impide mantener la distinción entre poder constituyente y constituido y habilitar un margen de pluralismo político que permita actuar al principio democrático y ejercer el derecho fundamental a la participación política.

30 Uno de los argumentos que se contenían en el mandato representativo liberal era brillantemente desarrollado por Benjamin Constant, que sostenía que los ciudadanos modernos no querían dedicar su tiempo a la cosa pública y preferían reservarlo a sus intereses privados. En cambio, García Guerrero estima que en el mandato de la democracia representativa de partidos el argumento se ha transformado porque los ciudadanos no son uniformes sino plurales y, en consecuencia, hay algunos que sí quieren dedicar su tiempo a los asuntos públicos (2000: 576 y 581; 2017b: 492 y 496).

31 Salas Hernández (1979), Santolaya Machetti (1988) y Carmona Contreras (1997). 


\section{EN LA UNIÓN ADUANERA Y EN EL CAMINO AL MERCADO COMÚN}

La afección a la democracia se extiende a toda la política comercial cuando se profundiza en la integración y se alcanza la fase de unión aduanera. Es habitual que una vez conseguida la fase de unión aduanera se inicie el proceso con objeto de alcanzar un mercado común. Por tanto, aquí se van a describir las consecuencias constitucionales que comienzan cuando la unión aduanera se encamina a mercado común y que solo se producen en su plenitud cuando se consigue esta última fase de la integración.

Los ámbitos materiales que afectan a la democracia se amplifican extraordinariamente; a las mercancías, a algunos servicios y a la política comercial se añaden la totalidad de los servicios y todas las materias necesarias para garantizar la libre circulación de trabajadores, capitales, así como para asegurar la competitividad y la igualdad en las condiciones básicas de ejercicio de la actividad económica. La extensión del ámbito material transferido a los órganos de la integración es mucho mayor que el reseñado literalmente, dada la conexión con otras muchas materias que se reclama para lograr la efectividad de las competencias transferidas. Por esta razón se crea ex novo un ordenamiento jurídico en el que se integran los estatales que, además, contribuyen al mismo implementado el derecho de la integración. Lo que lleva a establecer órganos ejecutivos, legislativos y judiciales de la integración. La necesaria creación de una infraestructura monetaria en esta fase implica la transferencia a la integración de parte de las políticas monetarias de los Estados.

El ataque a la democracia en esta fase es de considerable importancia. El tipo de norma que encabeza el ordenamiento jurídico de la integración es un tratado internacional y no una norma constitucional. El amplio ámbito material que literalmente se transfiere, más el que resulta ampliado de sus conexiones, el establecimiento del sistema de fuentes jurídicas y la creación de órganos legislativos, ejecutivos y judiciales exigen normas materialmente constitucionales; sin embargo, en vez de estas se emplea un tratado internacional. El resultado es que en lugar de operar el poder constituyente constituido lo hacen los Ejecutivos de los Estados miembros, mientras los Parlamentos estatales se encuentran en la disyuntiva de aceptar o rechazar un todo; poco hay que decir sobre la falta de legitimidad democrática de origen. Además, las normas constitucionales son abiertas, con una discrecionalidad, mayor o menor, según el margen de pluralismo político que ha conferido al legislador el constituyente ${ }^{32}$; frente a esto el tratado internacional es una norma cerrada, como las

32 La STC 11/1981, FJ 7, establece que la Constitución se presenta como un «marco de coincidencias lo suficientemente amplio como para que dentro de él quepan opciones 
del resto del ordenamiento jurídico, que persigue el principio de seguridad jurídica. La segunda consecuencia importante, por tanto, es una relevante pérdida de pluralismo político que dificulta, cuando no impide, la realización del principio democrático y el ejercicio de la participación política.

Un ataque a la democracia de este calibre tenía que ser contrarrestado de alguna manera, aunque lo fuera de forma insuficiente. Tres medidas parecen haberse adoptado. En concreto, la integración reconoce el derecho a abandonar la misma, mediante la denuncia de los tratados internaciones. Se mantiene la regla de la unanimidad en la toma de decisiones, lo que permite, junto a la anterior medida, salvaguardar en parte la soberanía (para evitar esta merma se debería haber traslado la soberanía de los pueblos de los Estados al resultante de la integración), concretamente mediante una soberanía compartida. Finalmente, la integración crea órganos como el ejecutivo, legislativo y judicial de la integración. El problema viene en el campo del legislativo y del judicial. El Parlamento lo es nominal pero no materialmente, ni controla al gobierno, ni legisla ni elabora el presupuesto, al menos con la intensidad que requiere una constitución racional normativa con forma de gobierno parlamentario. La consecuencia es un desplazamiento de los poderes del legislativo al ejecutivo. En el campo judicial se consagra un tribunal como máxima instancia del ordenamiento jurídico de la integración, órgano que tiene la última palabra. Se estima que una decisión de este calibre requiere de una norma constitucional, como sucede en los Estados federales en que la última instancia jurisdiccional se integra entre los órganos de la federación. Como vemos, las medidas no logran solventar en nada la distinción entre poder constituyente y constituido, ni el pluralismo político necesario para ejercitar el principio democrático y el derecho fundamental a la participación política.

\section{EN LA UNIDAD ECONÓMICA Y/O MONETARIA SUPRAESTATAL}

Ya sean cuatro o cinco las fases de la integración, sus consecuencias constitucionales sobre la democracia van a afrontarse tomando como referencia a la Unión Europea. En la fase de unidad económica se transfieren a la integración más materias, consecuencia del mayor estrechamiento de la infraestructura monetaria, relativas a las políticas macroeconómicas, monetarias y fiscales,

políticas de muy diferente signo». En la literatura jurídica véanse Hesse (1983: 33 y ss.), Böckenförde (1993: 17) y Aguiló Regla (2003: 32-34), con el que compartimos que algunas normas de la Constitución son cerradas. También sobre el carácter abierto de las normas constitucionales, Schneider (1987: 75-76). 
lo que implica que la integración dicta políticas regulatorias concretas. En la Unión, el paso a la unidad económica y monetaria supraestatal no ha sido simétrico, como ya se reseñó; el Reino Unido encabeza una serie de Estados que quedaron al margen. Esta decisión origina un cambio en el sistema de fuentes jurídicas, ahora se debe tener presente no solo el ordenamiento jurídico de la Unión, sino los acuerdos intergubernamentales en forma de tratados internacionales suscritos por los Estados de la eurozona, que se dotan también de una cierta estructura institucional en forma de órganos ejecutivos y legislativos ${ }^{33}$. La afección que esto tiene sobre la democracia ha sido ya reseñada a propósito de la fase de mercado común y se agrava en consecuencia.

En la unidad económica y monetaria supraestatal se transfieren la totalidad de las políticas monetarias, también las macroeconómicas y las fiscales porque aunque estas dos últimas pertenecen formalmente a los Estados integrantes, materialmente, como se han reseñado, son decididas en última instancia por las autoridades de la integración ${ }^{34}$. Una vez alcanzado este punto, se ha producido una completa desconstitucionalización de las constituciones económicas de los Estados miembros en favor de la integración. Como se ha reseñado anteriormente no se trata solo de la transferencia de la totalidad del ámbito material económico en favor de la Unión Europea, sino que para hacer efectiva esta transferencia se produce un vaciamiento de la mayor parte de las competencias en favor de la integración; esta detenta la inmensa mayoría, ya sea mediante regulación directa o a través de la obligación de implementar su derecho. Esta realidad se puede comprobar comparando, por ejemplo, las competencias que ejercita la Unión y las que corresponden al Estado español. Una simple lectura de la legislación española emanada de los ámbitos competenciales contenidos en los artículos 148 y 149 de la Constitución permite comprobar cómo la mayor parte de los mismos refleja la legislación de la Unión y cómo esta deja escasa discrecionalidad al legislador español cuando debe implementar el derecho de la Unión y, lógicamente, ninguna cuando la regulación europea es directa.

El ataque a la democracia que supuso la consecución del mercado común por la Unión Europea originó una reacción de esta para tratar de disminuirlo,

33 Menéndez Menéndez reseña cómo la práctica seguida desde la constitución de la eurozona ha sido objeto de reconocimiento formal en el Tratado de Lisboa, concretamente, en el Protocolo 14 sobre el Eurogrupo, anejo ahora a los tratados de la Unión Europea (2015: 160-161).

34 Para llegar a esta conclusión, en relación con la Unión Europea, es suficiente con analizar lo que señala Menéndez Menéndez a propósito de las políticas macroeconómicas y fiscales, especialmente en el caso de los Estados que incurren en desequilibrios macroeconómicos o déficit excesivos (2015: 149-160). 
al tiempo que se iniciaba el tránsito de mercado común, primero a unidad económica y después a monetaria. La Unión, consciente de las críticas del ataque que la integración suponía para la democracia, inició una serie de reformas destinadas a contrarrestarlo. Las principales trataron de transformar un Parlamento nominal en material, convirtiéndolo en colegislador en amplios ámbitos materiales y dotándolo de facultades de control frente al Ejecutivo comunitario $^{35}$. En segundo lugar, se introdujeron reformas para hacer posible la creación de partidos políticos de ámbito europeo ${ }^{36}$, que permitieran incrementar la participación de los ciudadanos europeos utilizándolos instrumentalmente. Finalmente, el Tratado de Lisboa incorporó la Carta de Derechos Fundamentales de la Unión ${ }^{37}$.

Sin embargo, al tiempo, y fruto de la fase de unidad económica y monetaria supraestatal, la Unión cambió la unanimidad de sus decisiones por mayorías cualificadas e, incluso, «minorías cualificadas». En ese mismo momento se culmina la desconstitucionalización de las constituciones económicas de los Estados y surge un marco económico de la Unión (el equivalente a la constitución económica de la Unión, término que no se emplea para evitar el efecto legitimador de las normas constitucionales) completamente cerrado. Este abandona, definitivamente, si es que previamente lo tuvo, el modelo de constitución económica intervencionista, propio de las constituciones de sus Estados miembros, y adopta el de la constitución económica de economía social de mercado en su versión ordoliberal, lo que se apuntala con la regla de oro de la estabilidad presupuestaria ${ }^{38}$, difícilmente comprensible en Estados cuyas constituciones se definen como sociales. Se

35 Martínez Alarcón, García Guerrero y Gordillo Pérez (2015: 460 y ss.).

36 El Tratado de Unión Europea, aprobado en Maastrich, en su artículo 138.A, alude a los partidos políticos como «importante factor para la integración de la Unión", pues «contribuyen a la formación de la conciencia europea y a expresar la voluntad política de los ciudadanos de la Unión»; precepto que hoy se encuentra recogido en el artículo 10.4 TUE. Además, hay que tener presente el Reglamento CE 2004/2003 del Parlamento Europeo y del Consejo, de 4 de noviembre de 2003, que regula el estatuto de los partidos políticos a escala europea y las normas relativas a su financiación, y la posterior modificación por el Reglamento CE 1524/2007, de 18 de diciembre (López de la Fuente, 2014).

37 Artículo 6TUE, que dispone: «La Unión reconoce los derechos, libertades y principios enunciados en la Carta de los Derechos Fundamentales de la Unión Europea de 7 de diciembre de 2000, tal como fue adaptada el 12 de diciembre de 2007 en Estrasburgo, la cual tendrá el mismo valor jurídico que los Tratados».

38 Entre la amplia literatura jurídica véanse López Garrido (2013) y Oehling de los Reyes y De Benito Aramburu (2016: 97-136). Sobre el desarrollo del artículo 
recogen los principios del ordoliberalismo y se resaltan las notas de economía abierta y competitiva, abrazando de esta forma el libre comercio, esto es, la globalización en sus dos etapas ${ }^{39}$.

El resultado de esta forma de realizar una unidad económica y monetaria supraestatal es que una serie de tratados internacionales crean un ordenamiento jurídico, se dotan de una declaración de derechos y libertades fundamentales, instituyen órganos ejecutivos, legislativos y judiciales, asumen la totalidad de las competencias económicas y, a su través, para hacerlas efectivas, reciben también la mayor parte de las competencias de los Estados. La sustitución de la unanimidad por distintos tipos de mayorías convierte prácticamente en soberano a la reunión de los jefes de Gobierno, que conocen de escasos límites provenientes del escueto control que pueden ejercer los Parlamentos nacionales y el europeo. Su único límite real sería la política monetaria y el control sobre las instituciones financieras, que queda en manos del Banco Central Europeo, que, dada su conformación jurídica, se sustrae del juego político y queda como un espacio inmune al principio democrático ${ }^{40}$. La única pervivencia de la soberanía popular de cada estado reside en la posibilidad de abandonar la Unión.

En esta fase, los tratados de la Unión contienen todas las normas materiales que son propias de una Constitución; el problema de emplear normas internaciones en lugar de constitucionales, que se ha relatado a propósito de la fase de mercado común, adquiere su máxima intensidad, afectando al poder constituyente y al constituido (las normas no son elaboradas por el primero sino por el Consejo, esto es, por los jefes de Gobierno de los Estados miembros). Se desvanece en buena parte de los ámbitos competenciales (los transferidos más los necesarios para hacerlos efectivos) el pluralismo político, de forma completa en el ámbito económico, y, consecuentemente, el margen de discrecionalidad con que debe contar el legislador, con lo que en estos campos solo cabe un disminuido ejercicio del principio democrático y de su concreción, el derecho fundamental a la participación política; específicamente la que se ejerce en un Parlamento Europeo que solo parcialmente legisla y controla al Ejecutivo.

135 y su incidencia en las comunidades autónomas, Medina Guerrero (2014: 189 y ss.).

39 Sobre todos estos aspectos, García Guerrero (2017a).

40 Menéndez Menéndez señala cómo, por ejemplo, el objetivo anual de inflación se establece por el Banco Central Europeo y no por el Parlamento (2015: 142-143). Desde un perfil constitucionalista, Giménez Sánchez (2015: 567-585). Véase también Binder y Gortsos (2016). 


\section{EN LA SEGUNDA ETAPA DE LA GLOBALIZACIÓN, EN LOS ACUERDOS ENTRE BLOQUES ECONÓMICOS}

Con estos problemas constitucionales para la democracia encima de la mesa y sin que se vislumbre solución se inicia la segunda etapa de la globalización, esto es, el tercer ataque al principio democrático en Europa: la ausencia de democracia interna en los partidos políticos ${ }^{41}$ y los dos generados por la globalización. Aunque todavía requiere de mayor estudio, es muy posible que los nuevos acuerdos de libre comercio tengan más consecuencias para la democracia que los de la primera etapa de la globalización. Así parece indicarlo la creación de un órgano ejecutivo, la implementación legislativa que conllevan y la previsión de órganos arbitrales o jurisdiccionales para la resolución de conflictos. Si así fuera resultarían más afectados alguno de los actores, como potencias, Estados Unidos, expotencias, Rusia, o emergentes, China. Y qué decir cuando el actor es una integración de máxima intensidad como la Unión Europea. A los problemas no resueltos habría que añadir que este tipo de acuerdos es negociado por el Ejecutivo de la Unión, bajo orden e instrucciones del Consejo, y su aprobación corresponde a la reunión de los Ejecutivos de los Estados miembros, esto es, al Consejo y al Parlamento Europeo ${ }^{42}$, su forma jurídica es la de tratado internacional de la Unión Europea. Es pronto para pronunciarse sobre sus consecuencias constitucionales, aunque, si son tan distintos como se piensa respecto a los de la primera etapa de la globalización, sus consecuencias constitucionales pueden ser mutatis mutandis similares a las que se presentan en la evolución de unión aduanera a mercado común, con el agravante de que el ciudadano de un Estado solo participará muy indirectamente a través de su Parlamento nacional y del europeo.

41 El autor sostiene que el primer ataque a la democracia proviene de los partidos y de la doctrina. Los primeros porque se niegan a serlo, al no arbitrar mecanismos para una efectiva democracia interna que habilite la participación en el interior de esta organización a los militantes del partido. La segunda, esto es, la doctrina porque se niega a reconocer que los Gobiernos parlamentarios europeos surgidos tras la Segunda Guerra Mundial operan en una democracia representativa de partidos; las posiciones que se combaten siguen aferradas a la democracia representativa liberal que desapareció de Europa y sigue manteniéndose en la actualidad en Estados Unidos.

Para llegar a esta conclusión se requiere una interpretación sistemática entre los artículos, 218.6.a).v), que determina el procedimiento dentro de la Unión para concluir un tratado internacional y, más concretamente, requiere la aprobación del Parlamento Europeo en los ámbitos sujetos al procedimiento legislativo ordinario, y el 207 que incluye a la política comercial común dentro del procedimiento legislativo ordinario, al requerir reglamento (Martínez Alarcón, 2015: 327-332). 


\section{EL ATAQUE A LA DEMOCRACIA NO AFECTA POR IGUAL A TODOS LOS ESTADOS}

En Estados Unidos el ataque a la democracia es de baja intensidad, solo se producen aquellas afecciones que se han descrito a propósito de la primera etapa de la globalización, cuando un Estado firma un acuerdo de libre comercio. Más intensas pueden ser las consecuencias si es cierta la tesis que aquí se presume de que existe una clara diferencia entre los acuerdos de libre comercio de la primera y de la segunda etapa de la globalización.

El Reino Unido se quedó en la fase de unidad económica estatal y renunció a la integración monetaria, encabezando un reducido número de Estados de la Unión. Es significativo resaltar que el mantenimiento de las competencias monetarias le permitió no solo ejercitarlas sino mantener, a su través, buena parte de su independencia en las políticas macroeconómicas y fiscales, lo que disminuyó gran parte del ataque a la democracia que implicaba el paso de la fase de mercado común a unidad económica supraestatal. El resto del embate trató de evitarlo mediante el acuerdo alcanzado con la Unión en febrero de $2016^{43}$, que, sometido a referéndum el pasado 23 de junio, desembocó en el conocido brexit. En definitiva, el Reino Unido ha decidido poner fin a los ataques al principio democrático abandonando la Unión Europea ${ }^{44}$, aunque, cuando se escriben estas líneas, todavía no ha ejercitado el procedimiento previsto en los tratados ${ }^{45}$.

43 Consejo Europeo (2016). Préstese especial atención a los anexos I, II y VI. ANEXO I. Decisión de los jefes de Estado o de Gobierno, reunidos en el seno del Consejo Europeo, relativa a un nuevo régimen para el Reino Unido en la Unión Europea. Sección A. Gobernanza Económica. Sección B. Competitividad. Sección C. Soberanía. Sección D. Prestaciones Sociales y libre circulación. Sección E. Aplicación y disposiciones finales.

44 Se requerirán amplios estudios para determinar las diversas causas del abandono por parte del Reino Unido de la Unión, aunque aquí solo se hace referencia a la que incide en el objeto de la investigación. No obstante, en las élites británicas siempre ha estado muy presente el problema del déficit democrático de la Unión, aunque lógicamente no es este un principio que por sí solo enganche a las mesas, lo que explica la amplia utilización en la campaña del brexit del argumento de la inmigración. Sobre esta materia véase el número monográfico de El Cronista del Estado Social y Democrático de Derecho (2016).

El artículo 50.1 TUE prevé que los Estados miembros podrán decidir retirarse de la Unión de conformidad con sus respectivas normas constitucionales. Sobre la materia, véase López Castillo (2015: 49), que señala: «Recibida la notificación del Estado que invoque la cláusula de retirada habría que acordar unas orientaciones con base en las cuales, siguiendo el procedimiento previsto en el artículo 218.3 TFUE (exigencia de 
Todos los países de la eurozona sufren el ataque a la democracia que supone un nivel de integración de unidad económica y monetaria supraestatal. No obstante, son discernibles, entre ellos, tres niveles. Alemania logra contener parte del embate a la democracia en cuanto líder de la integración ${ }^{46}$ y ha llegado a retrasar decisiones de los órganos de la Unión, a la espera de que se pronunciara su Parlamento ${ }^{47}$ o su tribunal constitucional ${ }^{48}$. En el extremo opuesto, mayor intensidad en el ataque a la democracia, se sitúan los países periféricos de Europa, como Italia, Irlanda o España, que han incurrido en desequilibrios macroeconómicos y en déficit excesivo, lo que ha llevado a una completa pérdida de las competencias macroeconómicas y fiscales y a que los órganos ejecutivos de la Unión le impongan políticas concretas regulatorias; la situación ha sido todavía peor en dos de los rescatados, caso portugués y, con mayor intensidad si cabe, Grecia ${ }^{49}$. En una situación intermedia se sitúa la mayor parte de los Estados de la eurozona, como Francia u Holanda, que

mayoría simple del PE y cualificada del Consejo), se pudiese concretar lo relativo a la forma de la retirada anunciada sin desatender la previsión del marco comprensivo de la futura relación con la UE del Estado saliente».

Closa Montero destaca la existencia de procesos top down, en los que se transfieren políticas de la Unión a los Estados, y procesos bottom up, en los que se trasladan políticas de los Estados a la Unión; estos últimos procesos se han producido en el campo de la política fiscal y macroeconómica, así como en sus mecanismos de garantía institucional. Alemania ha transferido, para Closa, esas políticas nacionales a la Unión, lo que refleja su papel hegemónico en la integración (2014: 70). Aquí se estima que esto le ha permitido contener el embate a la democracia.

Yarza Simón relata que conforme establece la Sentencia del Tribunal Constitucional Federal de 12 de septiembre de 2012 (2 BvR 1390/12; 2 BvR 1421/12; 2 BvR 1438/12: 2 BvR 1439/12; 2 BvR 1440/12; 2 BvE 6/12; Urteil des Zweiten Senats), cada ayuda federal internacional o europea a gran escala debe ser aprobada por el Bundestag, por ejemplo, el rescate bancario a España con el Fondo Europeo de Estabilización Financiera (FEEF) fue aprobado el 19 de julio de 2012 por 573 votos (2012: 15).

48 Por ejemplo, a propósito de la aprobación del MEDE, del Tratado sobre la Estabilidad, Coordinación y Gobernanza de la Unión Económica y Monetaria, y la ratificación de la reforma del artículo 136 del TFUE, el Tribunal Constitucional pidió al presidente de la República el 21 de junio de 2012 que no sancionase las leyes que servían de base para ratificar los referidos acuerdos internacionales hasta que dictara sentencia, lo que finalmente llevó a cabo el 12 de septiembre del mismo año (Yarza Simón, 2012: 8 y ss.). Sobre el control del Tribunal Constitucional Federal alemán a propósito de los ultra vires del programa de integración alemán en la UE, véase López Castillo (2014: 117 y ss.). Sobre las consecuencias de incurrir en desequilibrio macroeconómico y déficit excesivo véase supra nota $10 \mathrm{y}$, especialmente, el texto que le sirve de soporte. 
ven menos limitadas sus políticas macroeconómicas y fiscales y a los que no se imponen políticas regulatorias concretas.

Hay también alguna diferencia reseñable entre los Estados de la eurozona por el nivel de control que tienen los Parlamentos estatales sobre sus Ejecutivos y sobre la negociación que estos hayan realizado ante el gobierno de la Unión $^{50}$. El que mayor control ejerce de facto, como se ha visto, es el alemán ${ }^{51}$. Finalmente, el ataque a la democracia viene también intensificado porque la Unión estableció la libertad de circulación de capitales no solo en el interior de la integración sino frente al exterior. El capital internacional se convierte en un instrumento de control de la ortodoxia económica de los Estados (en clave liberal), con más intensidad en aquellos que presentan un mayor endeudamiento exterior, y dentro de ellos resulta, por ejemplo, muy diferente la situación de España y de Italia; en el primero la mayor parte de la deuda pública está en manos extranjeras, mientras que en el segundo la titularizan mayoritariamente sus nacionales.

\section{ALGUNAS REGLAS O CONCLUSIONES SOBRE CÓMO LA GLOBALIZACIÓN ATACA A LA DEMOCRACIA}

La constitución racional normativa ha sobrevivido a los numerosos embates teóricos y empíricos que ha sufrido desde su creación hace algo más de dos siglos ${ }^{52}$. No se cree que esto ha sido por sus valores, esto es, los derechos y libertades fundamentales, incluido el principio democrático, ni por los límites al poder, incluido el más importante, el Estado constitucional de derecho, que hacen posible dichos valores; estos permiten su legitimidad y son un magnífico banderín de enganche de esta posición ideológica, pero no explican su supervivencia. Como se ha defendido en anteriores trabajos y bajo la estela de

50 Un estudio sobre la diferente intensidad de control que ejercitan los Parlamentos europeos sobre sus ejecutivos en Salvador Crespo (próx.).

51 Véase la Sentencia del Tribunal Constitucional Federal de 28 de febrero de 2012 (2 BvE 8/11; Urteil des Zweiten Senats), a propósito del control del Bundestag sobre el representante alemán en el Mecanismo Europeo de Estabilización Financiera; y la Sentencia del Tribunal Constitucional Federal de 19 de junio de 2012 (2 BvE 4/11; Urteil des Zweiten Senats), que profundiza en el artículo 23.2 de la Constitución sobre el deber del Gobierno de informar a las Cámaras de los asuntos europeos completamente y lo antes posible. Una breve reseña en Yarza Simón (2012: 4 y ss.).

52 Solozábal Echavarría (Apuntes de Cátedra) detalla que en el plano empírico deben destacarse los ataques de las monarquías restauradas, del fascismo y del marxismo, y en el plano ideológico los embates de las constituciones historicistas, sociológicas y positivistas. 
Weber y García Pelayo ${ }^{53}$, la constitución racional normativa sobrevive no solo por la defensa de estos valores sino porque contiene en su genoma el capitalismo, porque es la forma de organizar la comunidad que mejor garantiza el funcionamiento de este sistema económico ${ }^{54}$. Ahora bien, aunque es cierto que la constitución racional normativa está al servicio del capitalismo, no hay duda de que en la misma el poder económico se encuentra sometido al poder político.

Lo relevante hoy, en el nuevo orden mundial, es que por obra de la globalización se supera el marco estatal en el que opera el concepto liberal de constitución, técnicamente denominada «racional normativa», y en este nuevo marco caracterizado dominantemente por la globalización no se ha logrado que opere plenamente la constitución liberal. El ataque a la democracia está servido, esto es, a la soberanía popular, a la distinción entre poder constituyente y constituido, al pluralismo político, al principio democrático, a la regla de la mayoría y la minoría y, en consecuencia, al derecho fundamental a la participación política. Por esta razón no es descartable que sea cierto lo que se escucha cada vez con más frecuencia en los foros y en la calle: el poder económico está dominando al poder político.

Si fuera cierto este dominio del poder económico sobre el político, esto no sería igual en todo el mundo. La influencia del poder económico vendría modulada, en primer lugar, por el músculo del Estado afectado, no es igual Estados Unidos que un pequeño país con un PIB muy disminuido. Y principalmente por las dos reglas que se han extraído en anteriores escritos de la primera etapa de la globalización, más por el conocido trilema de Rodrik. No obstante, antes de exponerlas es necesario previamente llamar la atención sobre los diferentes tipos de constitución económica que se aplican en la actualidad.

La doctrina viene distinguiendo tres tipos de constitución económica: la liberal ${ }^{55}$, la marxista y la intervencionista. La constitución liberal es la primera que apareció y se basa en la libre iniciativa privada y en el axioma de que el mercado realiza la más eficiente asignación de recursos a través de las reglas de la oferta y la demanda; Estados Unidos sigue siendo el paradigma de este modelo. La constitución marxista, surgida en la URSS y que subsiste en China, Vietnam, Cuba y Corea del Norte, se fundamenta en la propiedad pública de los medios de producción y en la planificación, este modelo niega

53 Weber (1942: 297) y García Pelayo (1984: 38).

54 En posición similar, García Vitoria afirma: «[...] al mercado no le vale cualquier forma política, sino que necesita al Estado constitucional» (2008: 2).

55 López de Lerma Galán (2016: 39-60). 
la libertad de empresa y la propiedad privada ${ }^{56}$. La constitución intervencionista, propia de Europa occidental, aparece tras la Segunda Guerra Mundial, introduce en la economía la fórmula del Estado social y desconfía de que el mercado realice la más eficiente asignación de recursos, por lo que procede a regularlo e intervenirlo. No obstante, había un modelo de constitución económica que no se había aplicado hasta ahora, concretamente la economía social de mercado. El marco económico de la Unión ha acogido este tipo de constitución en clave ordoliberal; no obstante, aquí se emplea la expresión marco económico en lugar de constitución económica porque la legitimación no puede provenir de un tipo de norma como el tratado internacional, sino que requiere de normas constitucionales. Una vez diferenciados los diversos tipos de Constitución económica se pueden comprender mejor las dos reglas extraídas de la primera etapa de la globalización y aproximarse al trilema de Rodrik.

La primera regla: cuanto mayor es la sintonía ideológica de las constituciones económicas que se integran menos sufre la democracia.

La segunda regla es que a medida que se profundiza en la integración más sufre la democracia, aunque los efectos se atenúan o incrementan en virtud de la primera regla, esto es, dependiendo de la mayor o menor sintonía ideológica entre las constituciones económicas de los Estados integrados.

Por su parte, el profesor Rubio Llorente, en su discurso de investidura como doctor honoris causa por la Universidad de Valladolid ${ }^{57}$, incluyó a la globalización entre los tres grandes problemas del Derecho Constitucional actual y llamó la atención sobre la preocupación que la doctrina estadounidense mostraba a propósito de las integraciones económicas supraestatales; concretamente, sobre la obra de Rodrik y su conocido trilema, que podríamos traducir con alguna licencia como la soberanía, la democracia y las integraciones y su interdependencia, lo que le lleva a considerar inviable un incremento de las tres; así entre las varias opciones ve en una disminución de la integración la posibilidad de incrementar el contenido del principio democrático ${ }^{58}$ (precisamente, lo que hasta el brexit había intentado la democracia más antigua del mundo: el Reino Unido).

En este libro, el catedrático de Harvard estima que la integración euro quizá pueda combatir los mayores inconvenientes de la globalización, aunque el profesor Rubio se muestra más bien pesimista respecto de esta última

56 Pérez Hernández (2016: 61-95).

57 Rubio Llorente (2013: 5-9).

58 Rodrik (2011). 
afirmación ${ }^{59}$. Aquí se podría sostener una posición intermedia; los Estados, con la excepción quizá de Estados Unidos, no tienen músculo para imponerse a ese poder económico. La Unión Europea podría hacerlo, aunque actualmente su política va en sentido contrario, como se puede observar en este trabajo, lo que explica, quizá, las cuatro posiciones que se van adoptando. Una primera de raíz nacionalista, paradigmáticamente representada por el Frente Nacional en Francia, que abandonaría la integración para recuperar la soberanía. Una segunda británica de inspiración conservadora, que busca menos integración para preservar el ataque a la democracia, pero manteniendo el libre comercio; tras el brexit esta posición desaparece. Una tercera, en vías de creación, representada por Syriza en Grecia, Podemos en España y, a lo mejor, el Partido Laborista británico, que acaba de reclutar a Varoufakis como asesor económico ${ }^{60}$, que se centra en plantar cara al poder económico y variar la política económica de la Unión de forma, en opinión de muchos, radical. Frente a estas opciones, cabría una cuarta que pretende una reforma de la gobernanza de la Unión para superar el ataque al principio democrático o, en su defecto, de no ser posible (por el acierto del trilema de Rodrik), abrazar el Estado federal europeo, lo que terminaría de raíz con el ataque a la democracia.

El trilema de Rodrik y, especialmente, las dos reglas que se acaban de reseñar, muestran toda su virtualidad si se atiende a la Unión Europea, que es el único lugar del mundo donde se han alcanzado las dos últimas fases de integración: la unidad económica supraestatal y la unidad económica y monetaria supraestatal. Estas dos últimas fases se han alcanzado en clave liberal, es más, el marco económico de la Unión (el equivalente a la constitución económica) es un nuevo tipo de constitución económica: la economía social de mercado ${ }^{61}$, nunca antes aplicada, construida en clave ordoliberal ${ }^{62}$. Este marco económico entra en contradicción con las constituciones económicas intervencionistas

59 Rubio Llorente (2013: 9); pesimismo que proviene de la dificultad de alcanzar una unión política, como puede apreciarse en la jurisprudencia del Tribunal Constitucional alemán.

60 Guimón (2016).

61 Que la Constitución económica española marca grandes distancias con la economía social de mercado fue tempranamente señalado por Donges (1978) y por García Echevarría (1978: 55). En el mismo sentido, posteriormente, Óscar de Juan (1984: 139-141).

62 Closa Montero resalta cómo la gobernanza macroeconómica y fiscal de la UE se inspira en la doctrina del ordoliberalismo alemán que tiene un amplio consenso entre la clase política (CDU-CSU, SPD y FDP) y los economistas (2014: 70-71). Menéndez Menéndez señala: «La fuerte (aunque selectiva) impronta de la tradición constitucional ordoliberal alemana sobre la configuración de la Eurozona se refleja de forma especialmente intensa en la definición de los objetivos de la política monetaria» (2015: 142). 
propias de los países de la eurozona ${ }^{63}$. Además, este marco resalta los principios de competitividad y apertura, que se cree no operan solo internamente sino externamente, esto es, en el contexto de la globalización. Finalmente, hay que añadir que la libre circulación de capitales ad intra y ad extra de la eurozona refuerzan el mantenimiento de una ortodoxia liberal ${ }^{64}$, como ya se ha señalado, al tiempo que fortalecen el dominio del poder económico sobre el político.

Ahora bien, si fuera cierto que el poder económico está dominando al poder político, cabría preguntarse: ¿qué ideología tiene aquel? Si uno analiza el marco económico de la eurozona, es decir, la economía social de mercado, y los principios de apertura y competitividad, así como la libre circulación de capitales, puede presumir que está ante un sistema económico ordoliberal. Los principios reguladores del ordoliberalismo, en clave de Estado social ${ }^{65}$, y la ausencia de igualdad en las condiciones básicas de ejercicio de la actividad económica por los empresarios (con mayor intensidad fuera de la Unión pero también dentro), marcan distancias con la constitución económica liberal.

Hay razones para pensar que el ordoliberalismo no solo inspira a la Unión Europea sino también a la globalización. Adopción de la economía de mercado basada en la libre competencia (China, Vietnam, Cuba incipientemente), estabilidad de las divisas (objetivo de los bancos centrales desde el inicio de la globalización), mercados abiertos, es decir, libre comercio, garantías a la propiedad privada, libertad contractual, responsabilidad de los actores económicos (incumplida por los rescates bancarios) y, por último, continuidad de la política económica $^{66}$. Aparentemente ese poder económico respondería al ordoliberalismo.

63 Menéndez Menéndez (2015: 172-174).

64 Menéndez Menéndez señala concretamente que la disciplina liberal en política fiscal vendría dada porque el capital internacional no prestaría a instituciones públicas que presentaran riesgos (2015: 163).

65

El ordoliberalismo para alcanzar un buen funcionamiento del sistema económico basado en la libre competencia identifica dos tipos de principios: los constitutivos y los reguladores. Estos últimos requieren el establecimiento de una agencia pública en defensa de la competencia que tenga capacidad para disolver monopolios o, al menos, para controlar su comportamiento en los mercados; una política fiscal con un impuesto progresivo sobre la renta; una política de protección del medio ambiente; y la corrección de situaciones anómalas en el mercado laboral (por ejemplo, el establecimiento de un salario mínimo). Véase al respecto Eucken (1992 y 1982: 115 131). También Gordillo Pérez y Canedo Arrillaga (2013: 163-183), que cita los anteriores trabajos.

66 Este párrafo refleja los principios constitutivos del ordoliberalismo, véase al respecto la literatura jurídica citada supra nota 65. 
No obstante, si se repara en el ideario económico de Silicon Valley, es difícil saber cuál es la ideología del poder económico que preside la globalización. Tres ideas base inspiran su concepción de la globalización: el incumplimiento de la ley, el ataque a la competencia y, como consecuencia, la búsqueda de los monopolios; lo que le sitúa claramente en contra de postulados básicos del ordoliberalismo.

Así Kalacnick, fundador de Uber, se dirige a la conquista planetaria incluso incumpliendo la ley, como Google, Facebook, Apple y Airbnb. Hablan de «una revolución comparable con la industrialización del siglo XIX». Su objetivo no es el dinero sino un futuro mejor para la humanidad, «aborrecen la política y consideran que la regulación no es solo un obstáculo sino un anacronismo». Thrun, el ingeniero más importante del laboratorio Google y hombre de confianza de Larry Page, presidente de esta compañía, dice que la política es el gran enemigo, «las reglas se dictan para consolidar las estructuras existentes. Nosotros intentamos eludirlas». Peter Thiel, el ideólogo de Silicon Valley, fundador de Paypal, que financió a Mark Zuckerberg en Facebook, en su libro Cómo inventar el futuro, mantiene como tesis fundamental que los monopolios son buenos, incluso deseables: «los monopolios creativos hacen posible que aparezcan nuevos productos beneficiosos para todos. La competencia supone que no [...] habrá beneficios para nadie [...]». Su consejo más importante para aquellos que quieren crear una empresa es que busquen un mercado que puedan dominar, construyendo un monopolio, e intenten conservarlo tanto tiempo como sea posible ${ }^{67}$.

\section{IV. ¿ंPUEDE OFRECER EL DERECHO CONSTITUCIONAL ALGUNA RESPUESTA AL EMBATE A LA DEMOCRACIA? BREVE REFLEXIÓN}

Si se atiende al ataque más grave a la democracia, el posible dominio del poder económico sobre el político, hay que diferenciar si este es de inspiración ordoliberal o radical (Silicon Valley). Al primero, el derecho constitucional le puede exigir el cumplimiento de uno de los axiomas del capitalismo: la igualdad en las condiciones básicas de ejercicio de la actividad económica. Esto exige determinar qué deben entenderse por condiciones básicas de ejercicio de la actividad económica. También puede exigirle que el sistema económico esté al servicio de los valores constitucionales, es decir, que suministre los recursos necesarios para su eficacia real. Al poder económico radical, al inspirado en Silicon Valley, habría que exigirle lo anterior, así como hacerle cumplir la ley, garantizar la competencia y disolver los monopolios.

67 Schulz (2015). 
No obstante, hay que advertir que las respuestas que ahora puede ofrecer el derecho constitucional no pueden pasar de ser meras propuestas que intensifiquen el debate doctrinal para tratar de obtener soluciones razonables que subsanen o limiten, en la medida de lo posible, el ataque al principio democrático.

Las propuestas que aquí se esbozan como objeto de debate están presididas por una serie de principios: deben ser proporcionadas, según nos encontremos en la primera globalización o en la segunda y atendiendo al nivel de integración en que nos encontremos. Tienen que garantizar el control del Parlamento sobre el Ejecutivo, en la medida en que la globalización desplaza poderes del Legislativo al Gobierno. Finalmente, las principales decisiones que en este ámbito se adoptan es necesario que cuenten con quorums legislativos reforzados o con quorums análogos a los que se exigen para las reformas constitucionales, dado que restringen o vacían de contenido al pluralismo político y afectan a materias que deben ser reguladas por normas materialmente constitucionales (la mayoría simple exigida en el referéndum británico confirma la necesidad de quorums reforzados).

La Unión Europea, China y Estados Unidos parecen los únicos actores capaces de evitar el hipotético dominio del poder económico sobre el político. Los dos últimos Estados no han procedido, todavía, a integraciones de la suficiente intensidad como para facilitar el dominio del poder económico sobre el político, aunque en Estados Unidos se debate sobre la influencia del poder económico en el político por los lobbies y la financiación privada de las campañas electorales. La orientación del marco económico de la Unión no parece dirigirse desde principios de los años noventa a evitar un hipotético dominio del poder económico sobre el político, lo que se ve favorecido por la ideológica liberal que preside este marco económico, por sus principios de economía abierta y competitividad, y por la libre circulación de capitales, estos dos últimos principios tanto hacia el interior como al exterior de la Unión.

En los acuerdos de libre comercio y unión aduanera hay que crear en el interior de cada Parlamento estatal comisiones parlamentarias que vigilen y controlen la actuación del Ejecutivo cuando mantiene negociaciones con los otros Gobiernos de la integración. Para que la publicidad que dimana de la actividad parlamentaria permita a los ciudadanos un conocimiento exhaustivo de lo que la integración implica, y para poder influenciar y condicionar la actuación del Gobierno durante la negociación, evitando de esta forma que la decisión parlamentaria, una vez concluido el acuerdo, se asemeje al decreto ley, esto es, que el Parlamento se vea obligado a aceptar o rechazar un todo. Alcanzado el acuerdo deberían exigirse quórums reforzados para el ingreso, más intenso en la segunda fase de integración, en la medida en que implica una pérdida de la competencia estatal en política comercial. 
Cuando una unión aduanera se dirige a la fase de mercado común es necesario crear un Parlamento de la integración elegido por sufragio universal, libre, igual, directo y secreto; la creación de partidos políticos que se correspondan con el ámbito de la integración; además, habría que crear en los Parlamentos de los Estados de la integración comisiones específicas de control de los acuerdos que se dirigen al mercado común, análogas, pero más intensas, a las relatadas a propósito del acuerdo de libre comercio y a la unión aduanera. El acuerdo para iniciar la integración que se dirige a un mercado común requeriría la aprobación en el Parlamento de cada Estado por un quórum análogo al de reforma constitucional y referéndum del pueblo. La democracia más antigua del mundo, el Reino Unido, siguió lo aquí propuesto para ratificar su ingreso en una unión aduanera que se dirigía a la fase de mercado común ${ }^{68}$. Irlanda, Dinamarca y Noruega también sometieron a referéndum el ingreso ${ }^{69}$.

La creación de un mercado común exigiría contar con partidos políticos que se correspondan con el ámbito territorial de la integración y dotarse de un auténtico Parlamento bicameral. Una Cámara que represente a los pueblos de los Estados y otra que integre a los jefes de Gobierno, representando a los territorios. Ambas Cámaras ejercerían la función legislativa, incluida la presupuestaria, y la de control al gobierno de la integración. Esta sería la única forma de garantizar una especie de soberanía compartida, la legitimidad democrática de ejercicio y el derecho fundamental a la participación política. La aprobación de la fase de mercado común exigiría una reforma constitucional agravada, en los Estados que diferencien dos tipos de reforma, y aprobar la misma mediante referéndum del pueblo. La reforma constitucional en cada Estado debería sancionar constitucionalmente a la comisión encargada de controlar la representación que el Ejecutivo desempeñe en la Cámara territorial de la integración. Esta comisión tendría que ser informada por el

68 Pérez Bustamante, entre otros, reseña cómo el Parlamento británico ratifica el Tratado de adhesión al Mercado Común Europeo del Reino Unido el 28 de octubre de 1971 con 358 votos a favor, 246 en contra y 22 abstenciones — se debe recordar que en el Reino Unido no hay diferencia formal entre la aprobación de leyes ordinarias y constitucionales - (1997: 148-150). Pese a que su ordenamiento constitucional no lo exigía, se celebró un referéndum de ratificación el 23 de abril de 1972, que fue aprobado con un $67,70 \%$ de votos a favor. El 1 de enero de 1973 se materializó el ingreso efectivo. Con mayor profundidad, véase Beneyto Pérez (2009).

El referéndum en Irlanda se celebró el 10 de mayo de 1972 y fue aprobado por el $83 \%$ de los electores; el de Dinamarca el 2 de octubre del mismo año y obtuvo el 56,7 \% de votos a favor; finalmente, el referéndum en Noruega se celebró los días 24 y 25 de septiembre de 1972, el ingreso fue rechazado por el 53,49\% de los votos (Pérez Bustamante, 1997: 150). 
Parlamento de la integración de su actividad legislativa. Asimismo, se debería mantener el derecho de veto de los Estados.

En la fase de mercado común habría que modificar las características de las normas que regulan la integración económica. Estas responden a la naturaleza jurídica de un tipo legislativo: el tratado internacional, esto es, son normas cerradas que buscan la seguridad jurídica; pues bien, aunque la naturaleza de la norma de la integración sea la de tratado internacional, es imprescindible, en esta fase de la integración, que los preceptos no sean cerrados sino que tengan un carácter abierto, como sucede con las normas constitucionales, para permitir un margen de discrecionalidad al legislador, es decir, que la norma contenga un mínimo de pluralismo político que permita salvar la realización del principio democrático y dote de efectividad al derecho fundamental a la participación política.

El siguiente paso o los dos siguientes, esto es, las fases de unidad económica y/o monetaria supraestatal, no se cree que puedan sostenerse mediante una profundización democrática de la integración. El derecho de veto debe dar paso a mayorías cualificadas. La intensidad de la integración obliga a pasar de la soberanía compartida a la soberanía de la unidad económica, las tensiones sobre la distinción entre poder constituyente y constituido, sobre el pluralismo político y sobre la legitimidad democrática de origen y de ejercicio son insostenibles ${ }^{70}$. En consecuencia, estas fases requerirían reformas constitucionales en los Estados miembros con sus correspondientes referéndums. Tras esta fase, y sobre los ámbitos competenciales cedidos, habría que convocar un Parlamento constituyente en el ámbito de la unidad económica que debería finalizar con la aprobación de una constitución federal sometida a referéndum del pueblo que se corresponda con el nuevo Estado.

Finalmente, respecto de la segunda etapa de la globalización, se sospecha que los acuerdos de libre comercio serían más intensos que algunas fases de integración de los de la primera etapa, al incluir un órgano ejecutivo, una intensa implementación legislativa y un órgano de arbitraje o jurisdiccional. Esta intensidad de integración parece recomendar que el acuerdo se adopte por los Parlamentos de los Estados con un quórum equivalente al de la reforma

70 Rubio Llorente señala: «El Derecho no es una pura estructura formal, sino una estructura dotada de un sentido necesario. Todo Derecho pretende ser justo». Esta «pretensión de validez (justicia) del Derecho es la proyección en este plano de la pretensión de legitimidad del poder, aunque los fundamentos de legitimidad del poder y del orden sean distintos, como en el conocido análisis weberiano. La obsesión positiva por excluir el problema de la legitimidad del ámbito de lo jurídico conduce por eso, inevitablemente, a una mutilación» (1991: 16-17). 
constitucional y que se sometan a referéndum. Cuando el acuerdo concierna a un Estado, la negociación del Ejecutivo debe ser controlada por su Parlamento de una forma similar a la reseñada a propósito de la fase de unión aduanera en tránsito a mercado común en la primera etapa de la globalización. Cuando el actor sea una unidad económica y/o supraestatal, el Parlamento bicameral debe controlar de forma análoga la actuación del Gobierno de la integración y los Parlamentos de los Estados la actuación de su Ejecutivo en la cámara de representación territorial.

\section{Bibliografía}

Aguiló Regla, J. (2003). Sobre el constitucionalismo y la resistencia constitucional. DOXA: Cuadernos de Filosofia del Derecho, 26, 32-34. Disponible en: https://doi.org/10.14198/ doxa2003.26.15.

Aragón Reyes, M. (1989). Constitución y democracia. Madrid: Tecnos.

Beneyto Pérez, J. M. (coords.) (2009). Desarrollo histórico y caracteres básicos de la Unión Europea. Naturaleza, valores, principios y competencias. En J. M. Beneyto Pérez, J. Maillo González-Orús y B. Becerril Atienza (coords.). Tratado de derecho y politicas de la Unión Europea (vol. I). Cizur Menor: Aranzadi Thomson-Reuters.

Binder, J. H. y Gortsos, C. V. (2016). The European Banking Unión: A compendium. C. H. Beck, Hart, Nomos.

Böckenförde, E. W. (1985). Democrazia e rappresentanza. Quaderni Costituzionali, 2, 227-263.

— (1993). Los métodos de interpretación constitucional. Inventario y crítica. En Escritos sobre derechos fundamentales. Baden-Baden: Nomos Verlagsgesellschaft.

Brewer-Carias, A. R. (1998). Las implicaciones constitucionales de la integración económica regional. En El derecho venezolano a finales del siglo XX. Caracas: Biblioteca de la Academia de las Ciencias Políticas y Sociales.

- (1999). Las exigencias constitucionales de los procesos de integración y la experiencia latinoamericana. Ponencia presentada al Congreso de Academias Iberoamericanas de Derecho, Córdoba.

Caamaño Domínguez, F. (1991). El mandato parlamentario. Madrid: Congreso de los Diputados.

Carmona Contreras, A. M. (1997). La configuración constitucional del Decreto-ley. Madrid: Centro de Estudios Políticos y Constitucionales.

Closa Montero, C. J. (2014). Los cambios institucionales en la gobernanza macroeconómica y fiscal de la UE: hacia una mutación constitucional europea. Revista de Estudios Politi$\cos , 165,65-94$.

Consejo Europeo (2016). Conclusiones del Consejo Europeo, 18 y 19 de febrero de 2016. Disponible en: http://www.consilium.europa.eu/es/meetings/european-council/2016/02/ EUCO-Conclusions_pdf/.

Contipelli, E. (2016). La Comunidad Andina de Naciones y la evolución del proceso de integración socioeconómico de Latinoamérica. Estudios de Deusto, 64 (1), 261-280. 
De Cabo Martín, C. (2009). Constitucionalismo del Estado Social y Unión Europea en el contexto globalizador. Revista de Derecho Constitucional Europeo, 11, 17-48.

Donges, J. B. (1978). El régimen económico de la Constitución española. Madrid: Centro de Estudios Constitucionales.

Eucken, W. (1982). A policy for establishing a system of free enterprise. En H. F. Wünsche (ed.). Standard texts on the social market economy (pp. 115-131). Stuttgart, New York: Gustav Fischer.

— (1992). The foundations of economics. History and theory in the analysis of economic reality. Berlin, New York: Springer. Disponible en: https://doi.org/10.1007/978-3-642-77318-1.

García Echevarría, S. (1978). El orden económico en la Constitución. Madrid: Centro de Estudios Constitucionales.

García Guerrero, J. L. (1990). Algunas cuestiones sobre la constitucionalización de los partidos políticos. Revista de Estudios Políticos, 70, 143-184.

- (1996). Democracia representativa de partidos y grupos parlamentarios. Madrid: Congreso de los Diputados.

— (2000). Democracia representativa y partidos políticos. En M. F. Massó Garrote, D. López Garrido y L. Pegoraro (coords.). Nuevo derecho constitucional comparado. Valencia: Tirant Lo Blanch.

- (2005). Integración económica y reforma constitucional. En Visión y análisis comparativo de reformas constitucionales en Iberoamérica (pp. 135-155). Santo Domingo: ONU, PUND.

- (2014a). Las integraciones económicas supraestatales y los acuerdos entre bloques económicos, en definitiva, la globalización como último embate al concepto racional normativo de Constitución. En E. J. Prats y M. V. Jimenián (eds.). Constitución, justicia constitucional y derecho procesal constitucional (liber amicorum en homenaje al profesor Dr. Juan Manuel Pellerano Gómez) (pp. 544-591). Santo Domingo: Instituto Dominicano de Derecho Constitucional y Librería Jurídica Internacional.

(2014b). Alguna reflexión a propósito del complejo ordenamiento jurídico de la Unión Europea y de los diferentes estatutos de derechos fundamentales, en perspectiva española. En A. Matilla Correa, L. G. Rodríguez Lozano y T. Garza Hernández (coords.). Estudios en homenaje a Germán Cisneros Farías (pp. 454-480). México: Universidad Autónoma de Nuevo León, Universidad de La Habana.

- (2014c). La publicidad (fundamentos y limites constitucionales). Valencia: Tirant Lo Blanch.

- (2017a). La desconstitucionalización de la Constitución económica española. En L. I. Gordillo Pérez (coord.). Constitución española e integración europea. Treinta años de derecho constitucional de la integración. Actas del XIV Congreso de la Asociación de Constitucionalistas de España. Valencia: Tirant lo Blanch.

- (2017b). Teorías de la representación política, democracia directa y partidos políticos. En M. F. Massó Garrote, D. López Garrido y L. Pegoraro (coords.). Derecho Constitucional Comparado. Valencia: Tirant Lo Blanch.

García Guerrero, J. L. y Martínez Alarcón, M. L. (2016). Constitución y mercado en la crisis de la integración europea: consideraciones preliminares. Estudios de Deusto, 64, 15-21.

García Pelayo, M. (1984). Derecho constitucional comparado. Madrid: Alianza Editorial. 
García Vitoria, I. (2008). La libertad de empresa. ¿Un terrible derecho? Madrid: Centro de Estudios Políticos y Constitucionales.

Giménez Sánchez, I. M. (2015). El Banco Central Europeo. En A. López Castillo (dir.). Instituciones y derecho de la Unión Europea (vol. I, pp. 567-585). Valencia: Tirant Lo Blanch.

Gordillo Pérez, L. I. y Canedo Arrillaga, J. R. (2013). La Constitución económica de la Unión Europea. Bases de un modelo en constante evolución. Cuadernos de Derecho Transnacional, 5 (1), 163-183.

Guimón, P. (2016). Corbyn incorpora a Varoufakis como asesor del Partido Laborista. El País, 29-2-2016. Disponible en: http://internacional.elpais.com/internacional/2016/02/29/ actualidad/1456750353_098216.html.

Heller, H. (1965). La soberanía. México DF: Universidad Nacional Autónoma de México.

Hesse, K. (1983). Escritos de derecho constitucional. Madrid: Centro de Estudios Constitucionales.

Kelsen, H. (2002). Esencia y valor de la democracia. Granada: Comares.

Krasner, S. D. (2001). Soberania: hipocresía organizada. Barcelona: Paidós.

Kriele, M. (1980). Introducción a la teoría del Estado. Buenos Aires: Depalma.

Lawrence, R. Z. (1996). Regionalism, multilateralism and deeper integration. Washington DC: Brookings Institutions.

López Castillo, A. (2014). Entre europeización y germanización. De la mutante jurisprudencia de apertura del Tribunal Constitucional Federal Alemán en perspectiva. Revista de Estudios Políticos, 165, 117-139.

- (2015). Instituciones y derecho de la Unión Europea, vols. I y III. Valencia: Tirant Lo Blanch.

López Castillo, A., Saiz Arnaiz, A. y Ferreres Comella, V. (2005). Constitución española y Constitución europea: análisis de la Declaración del Tribunal Constitucional (DTC-1/2004, de 13 de diciembre). Madrid: Centro de Estudios Políticos y Constitucionales.

López de la Fuente, G. (2014). Pluralismo politico y partidos políticos europeos. Granada: Comares. López de Lerma Galán, J. (2016). La Constitución económica liberal como garantía del libre mercado. Los derechos de propiedad privada y libertad de empresa. Estudios de Deusto, 64 (1), 39-60. Disponible en: https://doi.org/10.18543/ed-64(1)-2016pp39-60.

López Garrido, D. (dir.) y Martínez Alarcón, M. L. (coord.) (2013). Reforma constitucional y estabilidad presupuestaria (el artículo 135 de la Constitución española). Madrid: Centro de Estudios Políticos y Constitucionales.

Martínez Alarcón, M. L. (2015). Tercera parte. Caso práctico. En A. López Castillo (dir.). Instituciones y derecho de la Unión Europea (vol. III, pp. 327-332). Valencia: Tirant Lo Blanch.

Martínez Alarcón, M. L., García Guerrero, J. L. y Gordillo Pérez, L. I. (2015). El Parlamento Europeo. En A. López Castillo (dir.). Instituciones y derecho de la Unión Europea (vol. I, pp. 460 y ss.). Valencia: Tirant Lo Blanch.

Medina Guerrero, M. (2014). La constitucionalización de la regla del equilibrio presupuestario: integración europea, centralización estatal. Revista de Estudios Políticos, 165, 189-210.

Menéndez Menéndez, A. (2015). Integración económica e integración política. En A. López Castillo (dir.). Instituciones y derecho de la Unión Europea (vol. I, pp. 85-214). Valencia: Tirant Lo Blanch.

Oehling de los Reyes, A. y De Benito Aramburu, J. M. (2016). La modificación del artículo 135 de la Constitución española de 1978: aproximación jurídico-económica a las causas 
para una racionalización, estado de situación y resultados. Estudios de Deusto, 64 (1), 97-136. Disponible en: https://doi.org/10.18543/ed-64(1)-2016pp97-136.

Óscar de Juan, A. (1984). La Constitución económica española. Madrid: Centro de Estudios Constitucionales.

Pérez Bustamante, R. (1997). Historia de la Unión Europea. Madrid: Dykinson.

Pérez Hernández, L. (2016). La constitución económica socialista y sus fundamentos. Estudios de Deusto, 64 (1), 61-95. Disponible en: https://doi.org/10.18543/ed-64(1)-2016pp61-95

Rodrik, D. (2011). La paradoja de la globalización (Democracia y el futuro de la economía mundial). Barcelona: Antoni Bosch.

Rubio Llorente, F. (388). Globalización económica y reforma constitucional. Revista de Occidente, 388, 5-9.

Salas Hernández, J. (1979). Los Decretos-Leyes en la Constitución española de 1978. Madrid: Civitas.

Salvador Crespo, M. (próx.) El papel de las Cortes en la nueva gobernanza del euro. Madrid: Tirant Lo Blanch.

Santolaya Machetti, P. (1988). El régimen constitucional de los decretos-leyes. Madrid: Tecnos.

Sassen, S. (2001). ¿Perdiendo el control? La soberanía en la era de la globalización. Barcelona: Bellaterra.

Schneider, J. P. (1987). Continencia judicial y estructura normativa abierta del Derecho Constitucional. En A. López Pina (dir.). División de poderes e interpretación (hacia una teoria de la praxis constitucional (pp. 75-76). Madrid: Tecnos.

Schulz, T. (2015). Silicon Valley, la tierra del mañana. El País, 17-05-2015.

Taibo, C. (2016). Para entender el TIPP (una visión crítica del Acuerdo Transatlántico de comercio e inversiones). Madrid: Catarata.

Tajadura Tejada, J. (2006). La crisis de los derechos sociales en el contexto de la mundialización. Nuevas Políticas Públicas. Anuario Multidisciplinar para la modernización de las Administraciones Públicas, 2, 121-136.

Torres del Moral, A. (1988). Principios del derecho constitucional español. Madrid: Atomo.

Viciano Pastor, R. (2009). Problemas de legitimidad constitucional de las integraciones supranacionales. Cuadernos Constitucionales de la Cátedra Fadrique Furiol, 67, 91-99.

Weber, Max (1942). Historia económica general. México DF: Fondo de Cultura Económica.

Wyduckel, D. (1998). La soberanía en la historia de la dogmática alemana. Fundamentos. Cuadernos Monográficos de Teoría del Estado, Derecho Público e Historia Constitucional, 1, 203-294.

Yarza Simón, F. (2012). La democracia parlamentaria y el Tribunal de Karlsruhe: la crisis de la eurozona, el sistema electoral y el nombramiento de jueces constitucionales. Revista General de Derecho Constitucional, 15. 